\title{
NON-LINEAR FEM ANALYSIS FOR SHIP PANELS UNDER THERMAL LOADS
}

\author{
George-Ciprian Iatan \\ S.C. VARD S.A, Braila, \\ Celulozei Street, No. 01 A, \\ 810282, Romania, \\ E-mail: george.iatan@vard.com
}

\author{
Elisabeta Burlacu \\ EUXIN MARINE DESIGN \\ 21A-21B, Soveja St., 2nd floor, \\ 900415, Constanta, Romania, \\ E-mail: burlacu.elisabeta@gmail.com
}

\author{
Leonard Domnisoru \\ "Dunarea de Jos" University of Galati, \\ Faculty of Naval Architecture, Galati, Domneasca \\ Street, No. 47, 800008, Romania, \\ E-mail: leonard.domnisoru@ugal.ro
}

\begin{abstract}
During the past decade, welding remained the main technological procedure for joining steel components in shipbuilding industry. Though it has great benefits, welding is an aggressive process that introduces high stress and strains in the joined materials, causing distortion. Finite element method is an important instrument for predicting how structures are behaving under thermal loads. This paper is focused on studying the behaviour of small thickness ship panels, under straightening treatment, by performing thermalstructural-elastic-plastic analysis in Femap/NX Nastran. The proposed panel is tested under three different thermal loadings in order to study stresses and residual distortion.
\end{abstract}

Keywords: welding, FEM, thermal-structural-elastic-plastic analysis

\section{INTRODUCTION}

Literature suggestion for studying welding distortion offers two main directions for finite element analysis, namely: inherent strain method and thermal-structural-elasticplastic analysis. Although both methods have can be used, this research is using the second one, because has higher accuracy in predicting stress and strain of the material after thermal loading [1], [2].

Aiming to study the thermo mechanical behaviour of an upper deck structure, FEM analysis was used for a panel that was straightened using heat sources after welding, according to VARD Braila's straightening procedure [2].
For maximal accuracy, an experimental panel was welded and measured. Fig.1.1 and Fig.1.2. represents the 3D-view of the structure and defines the main dimensions from Table 1.

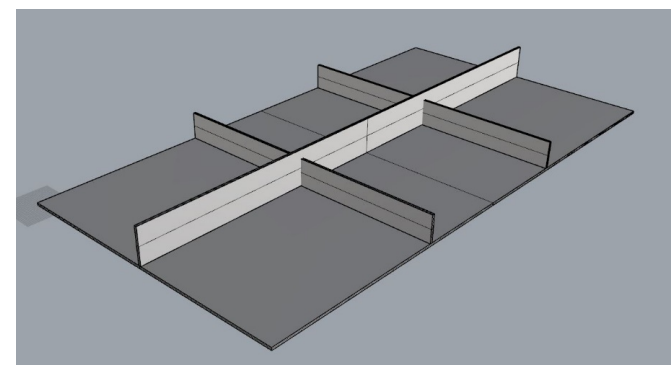

Fig. 1.1 3D view of the studied panel 


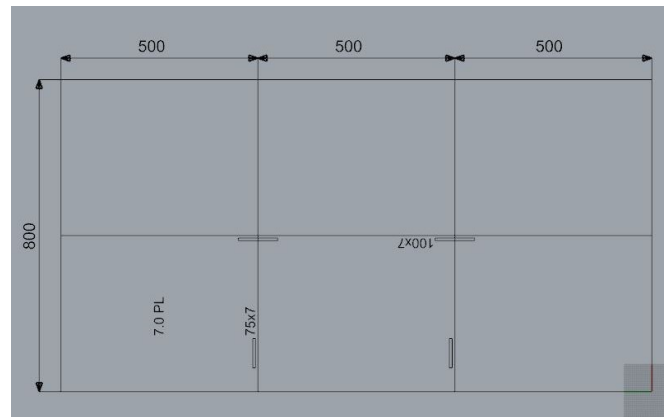

Fig. 1.2 Dimensions of the studied panel

Table 1 Components of the panel

\begin{tabular}{|c|c|c|}
\hline $\begin{array}{c}\text { Element } \\
\text { name }\end{array}$ & $\begin{array}{c}\text { Dimensions } \\
{[\mathbf{m m}]}\end{array}$ & $\begin{array}{c}\text { Quantity } \\
{[\mathbf{p c s}]}\end{array}$ \\
\hline Steel plate & $1,500 \times 800 \times 7$ & 1 \\
\hline Steel flatbar & $100 \times 7 \times 1500$ & 1 \\
\hline Steel flatbar & $75 \times 7 \times 400$ & 4 \\
\hline
\end{tabular}

\section{FEM ANALYSIS}

The thermal analysis was made in 78 loading steps, in order to describe oxy gas straightening process, which is usually applied in shipyards for distorted structures. For structural - heating iterations, at each time step, a non-linear scheme by Full Newton Raphson method is used [2]. Thermal loading was than extracted from temperature history of thermal analysis and used as the input in structural analysis. Residual deformations from each increment were handled to the nodes to describe updated structural model before the next temperature load [2].

The distortion of the experimental panel after welding was measured by using a highly accurate laser device and it is used for mapping the distorted structure in the Femap software. The experimental structure is presented in Figure 2.1 and the level of distortion in each of the measured points is presented in Figure 2.2.

Heat straightening simulation was chosen by adapting the temperature and heat iterations to the type of the structure and to the thickness of the components. The heating source reproduced is a straightening rake with three nozzles.

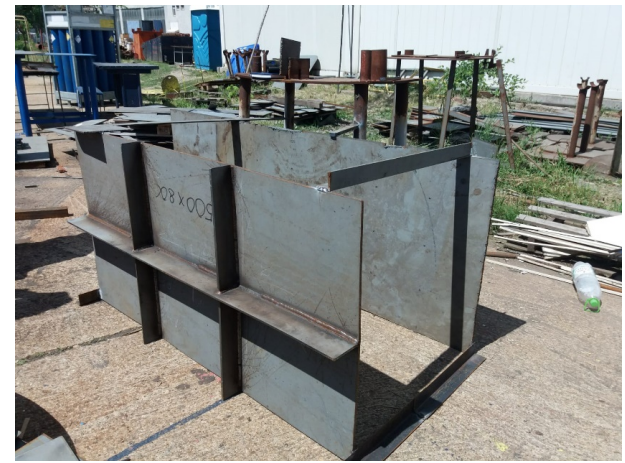

Fig. 2.1 Experimental panel

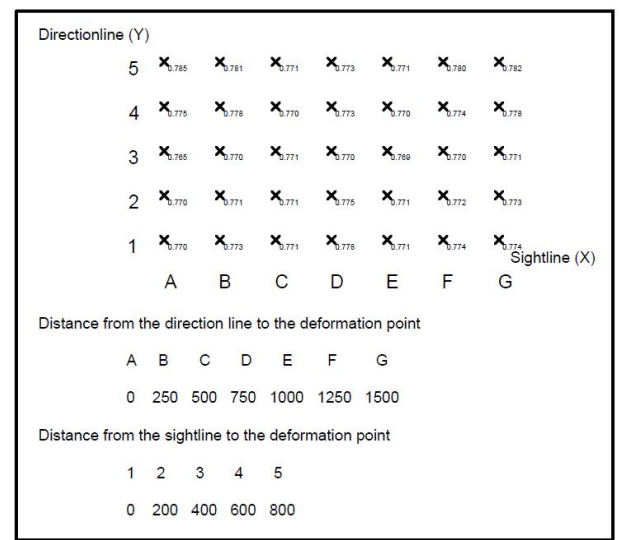

Fig. 2.2 Measured distortion on panel

Heat pattern was simulated on the opposite side of the plate, under the flatbar's position. The heating scheme started from the centre of the panel and went to the left and right sides in two positions. On the back of the transversal flatbars heating was applied, once at a time, starting from the centre of the structure to the margins. The full pattern is shown in Figure 2.3 [2].

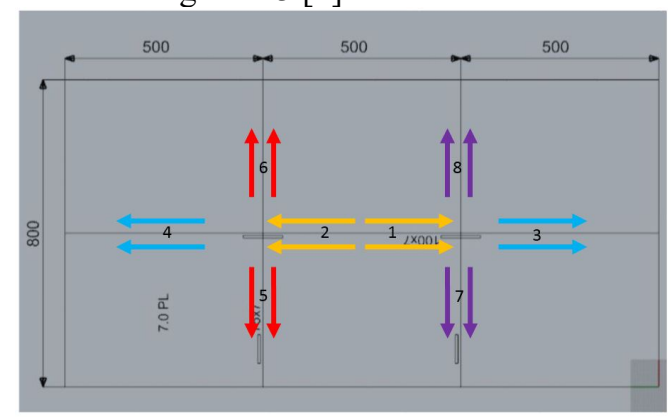

Fig. 2.3 Straightening pattern order

(c) Galati University Press, 2020 
Three different finite element analyses were performed for three thermal straightening cases, namely: $300^{\circ} \mathrm{C}, 550^{\circ} \mathrm{C}$ and $600^{\circ} \mathrm{C}$. The $300^{\circ} \mathrm{C}$ case has the purpose to highlight the phenomena in the elastic range of behaviour of the structure. Specific literature suggests to apply heat straightening treatments on steel, between the range of $590-620^{\circ} \mathrm{C}$ [3]. Considering the thickness of the steel being 7 $\mathrm{mm}$, straightening up to $600^{\circ} \mathrm{C}$ is enough in order to avoid material damage. For the purpose of studying the mitigation effect of the process during a smaller thermal loading, $550^{\circ} \mathrm{C}$ analysis is also performed [2].

Because the full analyses consist in multiple data results which can be consulted in the bibliography, from the various process stages only few data are included in paper.

Figure 2.4 from below, presents the thermal step 1 and 78 for the $300^{\circ} \mathrm{C}$ analysis. The other two cases are similar [2].

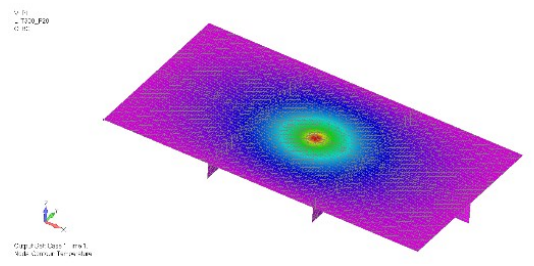

Fig. 2.4 a Thermal step $1-300^{\circ} \mathrm{C}$ analyse

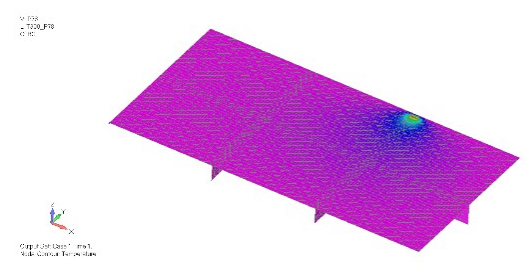

Fig. 2.4 b Thermal step $78-300^{\circ} \mathrm{C}$ analyse

Structural analysis is performed after the thermal analysis. Structural simulation is performed taking into consideration the results of the thermal analysis as input data, by following the pattern described below [2].

Each of the 78 thermal steps has its own structural analysis, by considering previous structural step results as the input data for the current one, using 100 iterations per step. Each step was divided in three temperature phases, namely:

1. $15^{\circ} \mathrm{C}$ considered as the initial temperature of the structure;

2. Loading, up to the target temperature of $300^{\circ} \mathrm{C}, 550^{\circ} \mathrm{C}$ and $600^{\circ} \mathrm{C}$;

3. Unloading, back to the initial temperature, considered $15^{\circ} \mathrm{C}$.

\section{RESULTS AND COMPARISONS}

The results of the structural-thermal analyses were grouped as: deformation, plastic strain, von Misses Stress and von Misses Strain. Each step of loading and unloading was distinctly represented at the same iteration. Again, because inserting all the results would be over the paper limits, exemplified results in various stages are selected and comparative diagrams regarding the centralized values are discussed.

Figure 3.1 highlights the named results for step 63 of the analyse, for the thermal loading case of $600^{\circ} \mathrm{C}$.

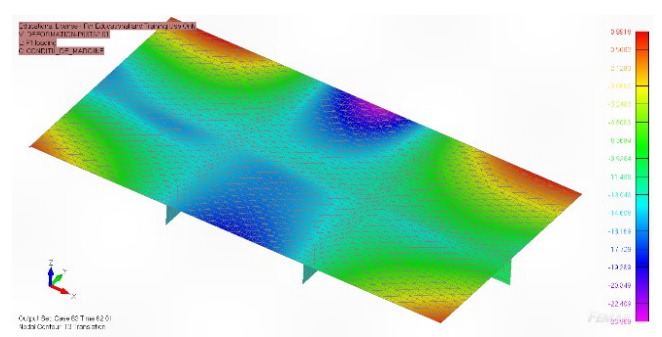

Fig.3.1.a. T $600^{\circ} \mathrm{C}$-DeformationStep63_loading

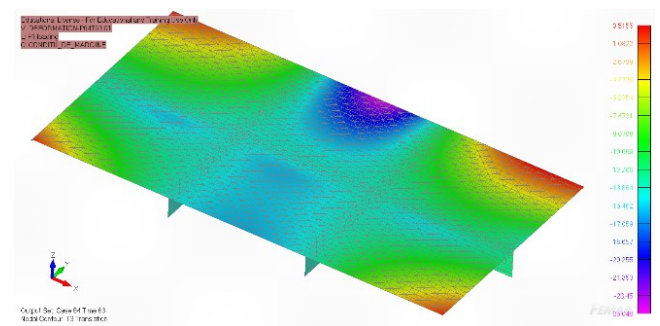

Fig.3.1.b. $\mathrm{T} 600^{\circ} \mathrm{C}$-DeformationStep63_unloading 


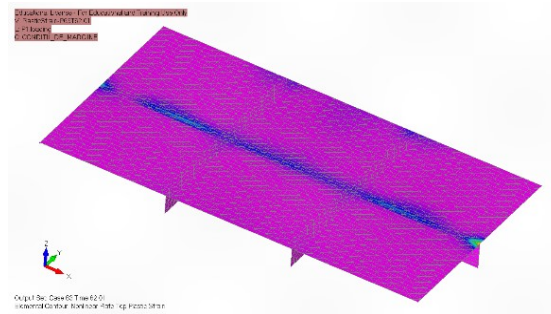

Fig.3.1.c. $\mathrm{T} 600^{\circ} \mathrm{C}$-Plastic strainStep63_loading

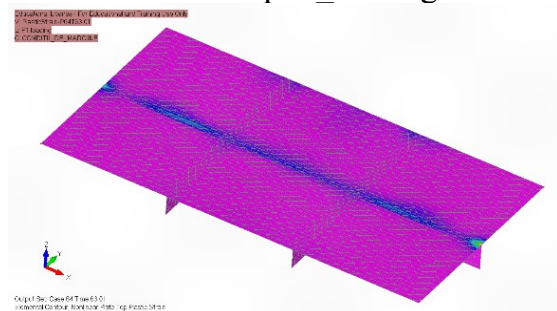

Fig.3.1.d. T $600^{\circ} \mathrm{C}$-Plastic strainStep63_unloading

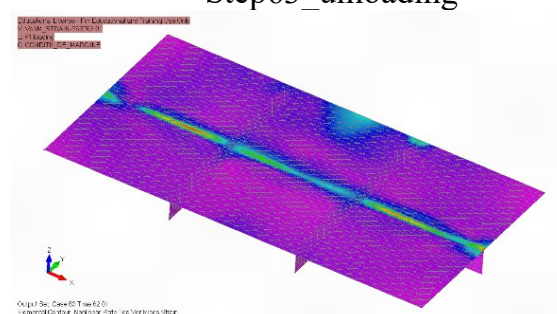

Fig.3.1.e. $\mathrm{T} 600^{\circ} \mathrm{C}$-vonM strainStep63_loading

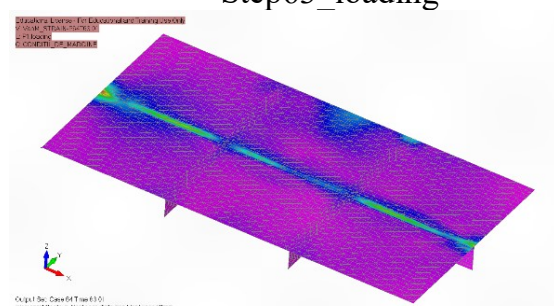

Fig.3.1.f. $\mathrm{T} 600^{\circ} \mathrm{C}$-vonM strainStep63_unloading

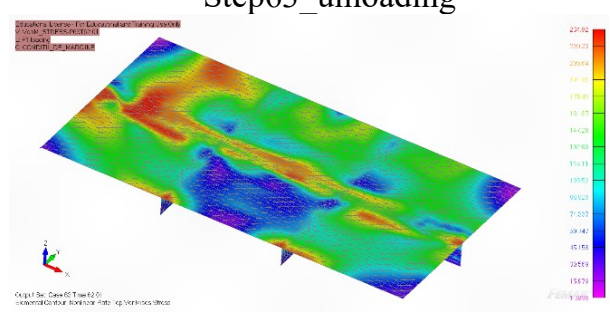

Fig.3.1.g. $\mathrm{T} 600^{\circ} \mathrm{C}$-vonM stressStep63_loading

98

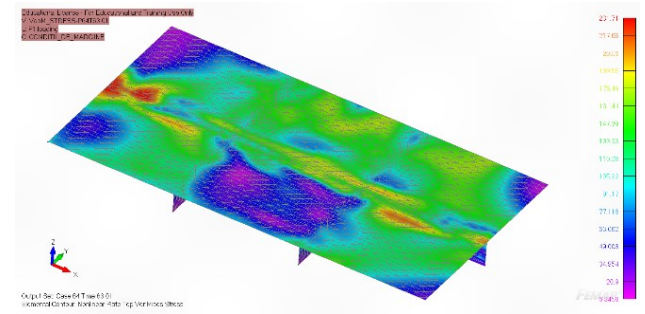

Fig.3.1.h. $\mathrm{T} 600^{\circ} \mathrm{C}$-vonM stressStep63_unloading

The results are synthesized at 9 points / nodes on the panel, for the $300^{\circ} \mathrm{C}, 550^{\circ} \mathrm{C}$ and $600^{\circ} \mathrm{C}$ thermal loads. In Figure 3.2 the considered nodes are highlighted. Table 2 describes the coordinates of the selected nodes.

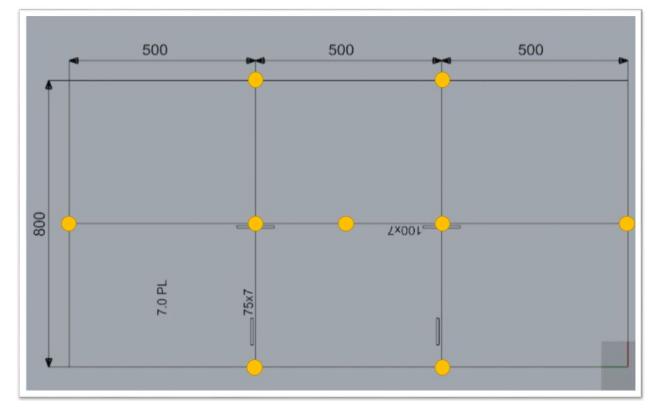

Fig. 3.2 Considered nodes for comparison

Table 2 Coordinates of the considered nodes

\begin{tabular}{|c|c|c|c|}
\hline Point ID & $\mathbf{X}$ & $\mathbf{Y}$ & $\mathbf{Z}$ \\
\hline 1518 & 750 & 400 & 0.77 \\
\hline 2416 & 1000 & 400 & 0.769 \\
\hline 1278 & 500 & 400 & 0.771 \\
\hline 3268 & 1500 & 400 & 0.771 \\
\hline 716 & 0 & 400 & 0.678 \\
\hline 1363 & 500 & 0 & 0.771 \\
\hline 244 & 500 & 800 & 0.771 \\
\hline 2501 & 1000 & 0 & 0.771 \\
\hline 2306 & 1000 & 800 & 0.771 \\
\hline
\end{tabular}

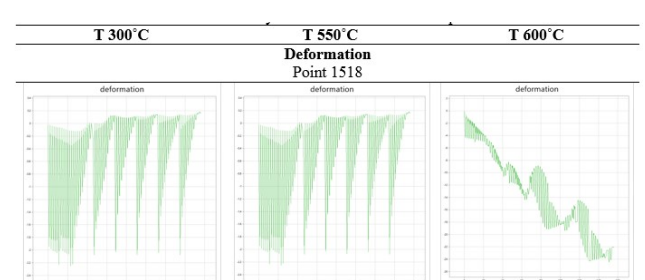

Fig. 3.3.1.a. Deformation in point 1518

(C) Galati University Press, 2020 


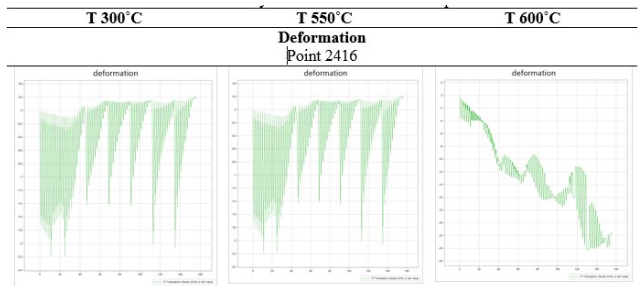

Fig. 3.3.1.b. Deformation in point 2416

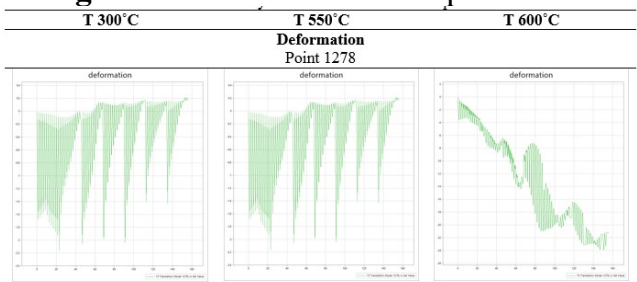

Fig. 3.3.1.c. Deformation in point 1278

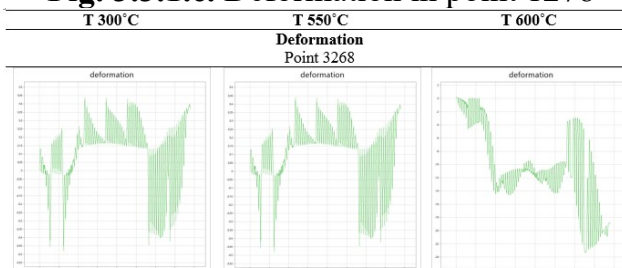

Fig. 3.3.1.d. Deformation in point 3268

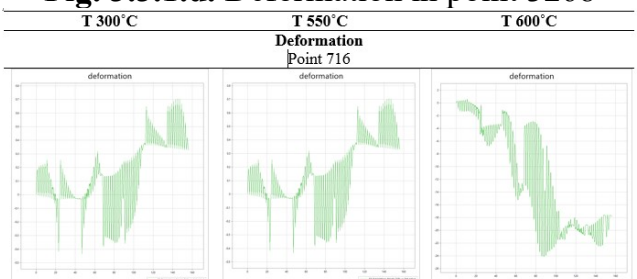

Fig. 3.3.1.e. Deformation in point 716

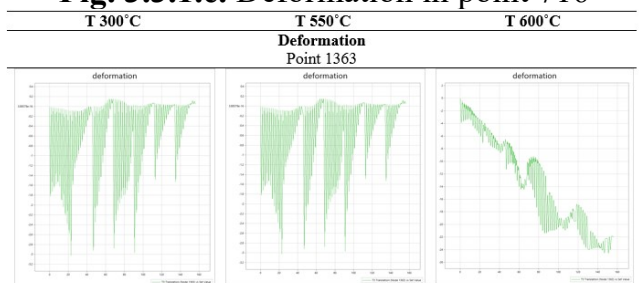

Fig. 3.3.1.f. Deformation in point 1363

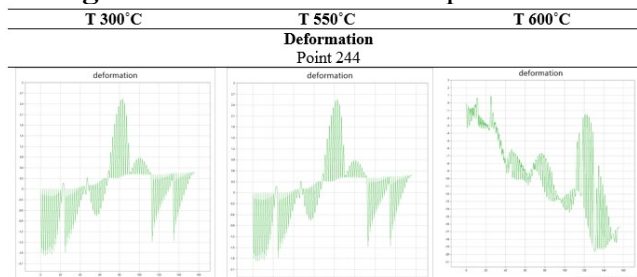

Fig. 3.3.1.h. Deformation in point 244

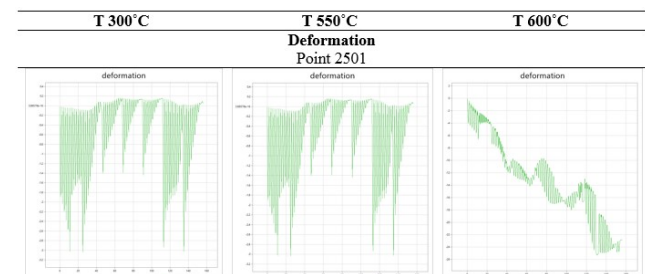

Fig. 3.3.1.i. Deformation in point 2501

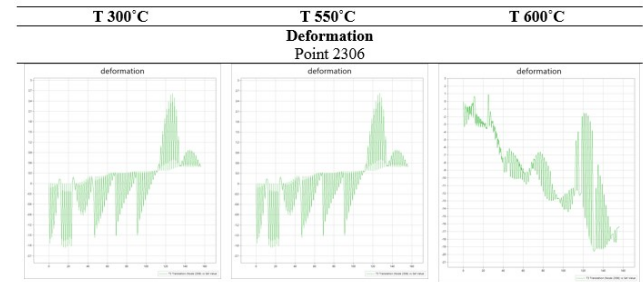

Fig. 3.3.1.j. Deformation in point 2306

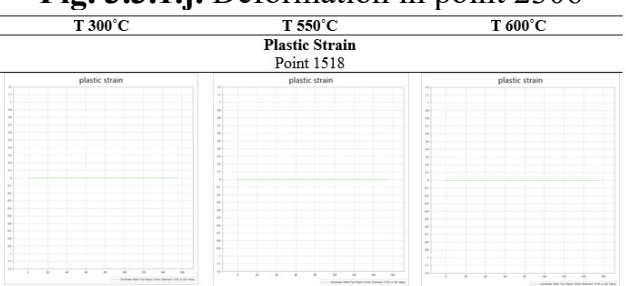

Fig. 3.3.2.a. Plastic strain in point 1518

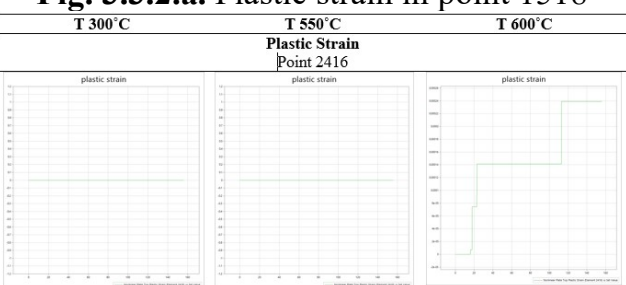

Fig. 3.3.2.b. Plastic strain in point 2416

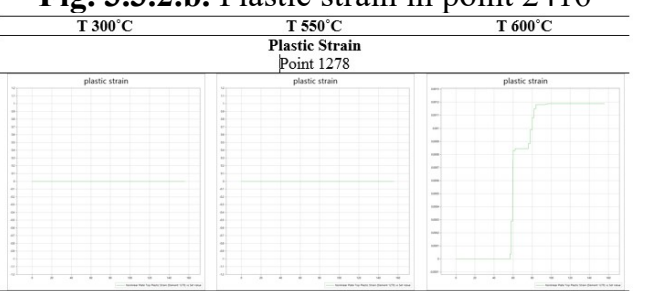

Fig. 3.3.2.c. Plastic strain in point 1278

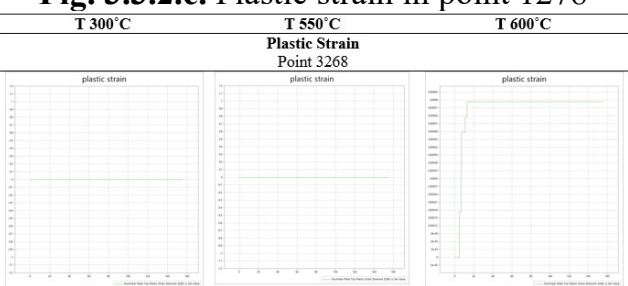

Fig. 3.3.2.d. Plastic strain in point 3268 


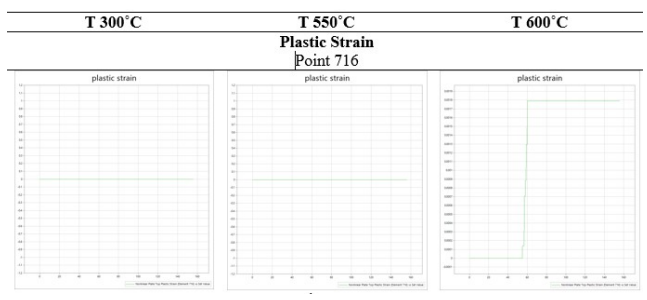

Fig. 3.3.2.e. Plastic strain in point 716

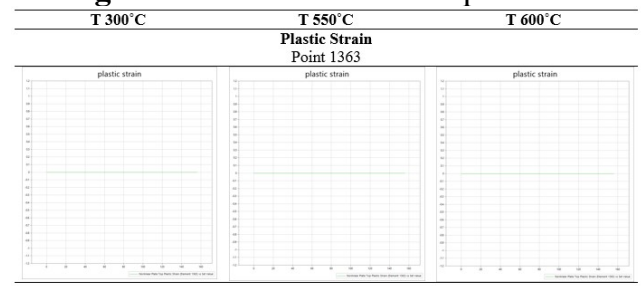

Fig. 3.3.2.f. Plastic strain in point 1363

\begin{tabular}{ccc}
\hline T300 & T 550 & T \\
\hline & $\begin{array}{c}\text { Plastic Strain } \\
\text { Point 244 }\end{array}$ & \\
\hline & & \\
\hline
\end{tabular}

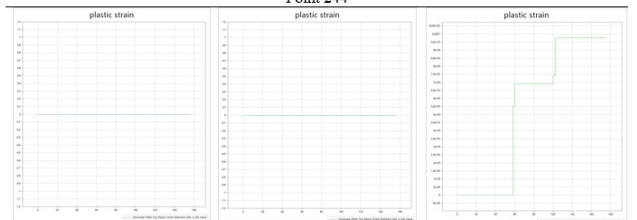

Fig. 3.3.2.g. Plastic strain in point 244

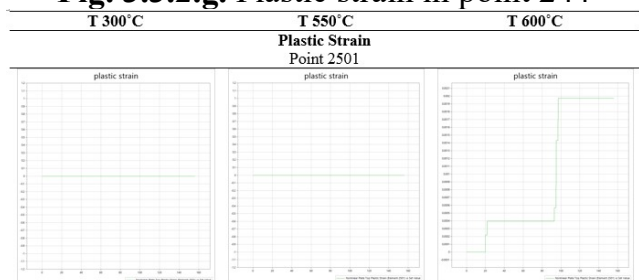

Fig. 3.3.2.h. Plastic strain in point 2501

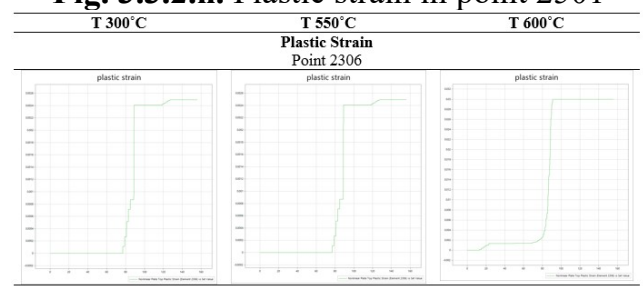

Fig. 3.3.2.i. Plastic strain in point 2306

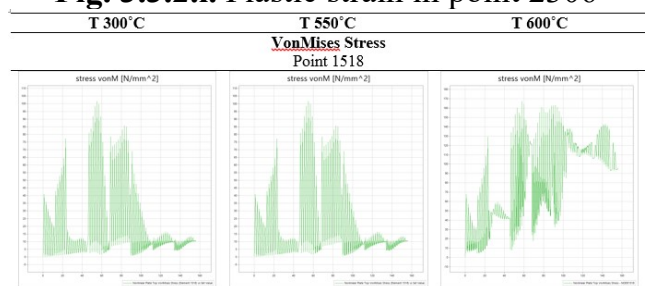

Fig. 3.3.3.a. VonM Stress in point 1518

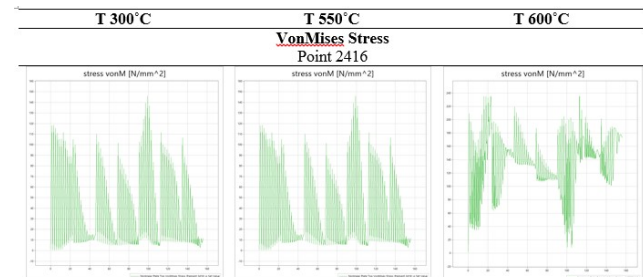

Fig. 3.3.3.b. VonM Stress in point 2416

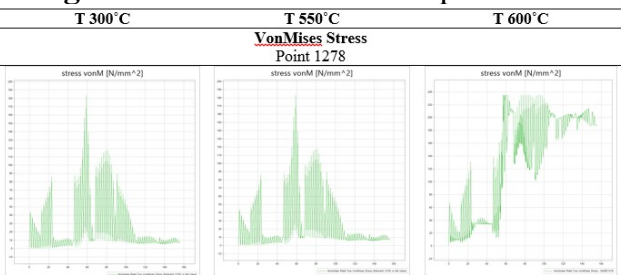

Fig. 3.3.3.c. VonM Stress in point 1278

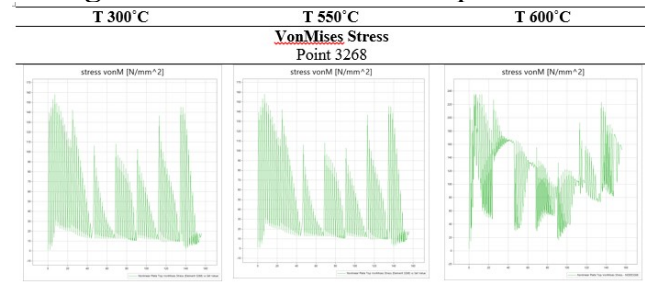

Fig. 3.3.3.d. VonM Stress in point 3268

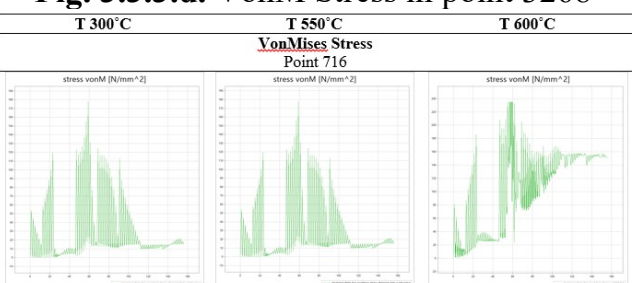

Fig. 3.3.3.e. VonM Stress in point 716

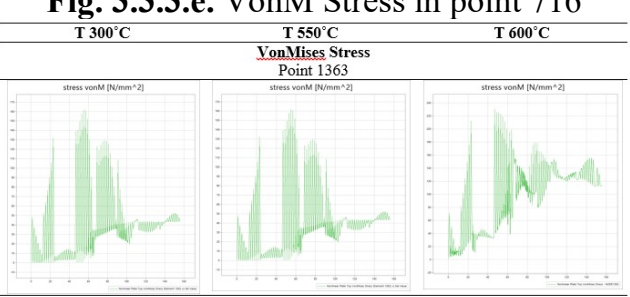

Fig. 3.3.3.f. VonM Stress in point 1363

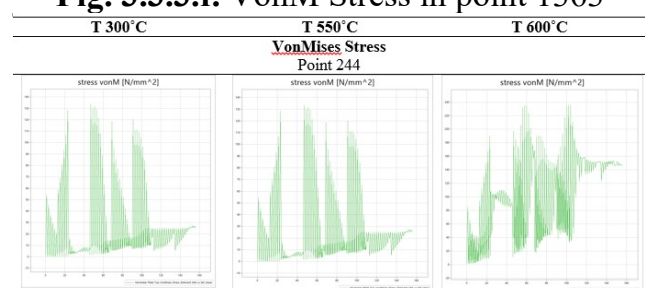

Fig. 3.3.3.g. VonM Stress in point 244

(C) Galati University Press, 2020 


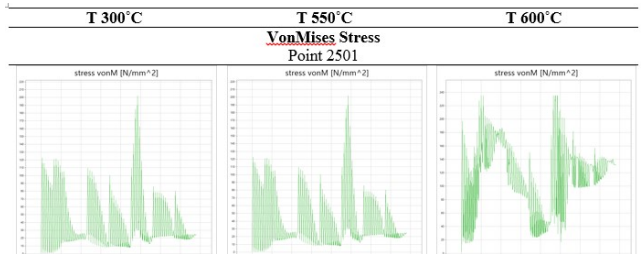

Fig. 3.3.3.h. VonM Stress in point 2501

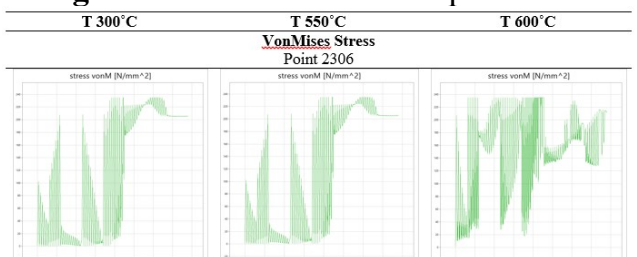

Fig. 3.3.3.i. VonM Stress in point 2306

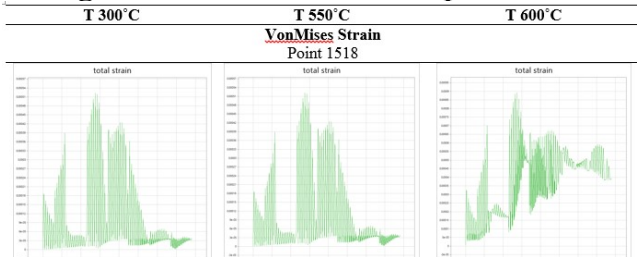

Fig. 3.3.4.a. VonM Strain in point 1518

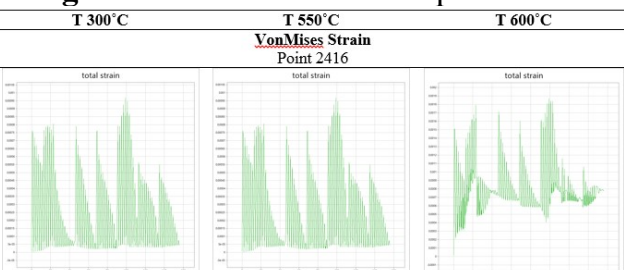

Fig. 3.3.4.b. VonM Strain in point 2416

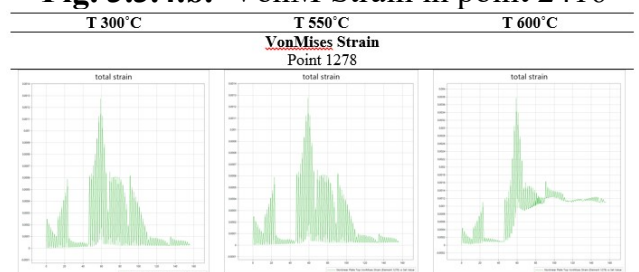

Fig. 3.3.4.c. VonM Strain in point 1278

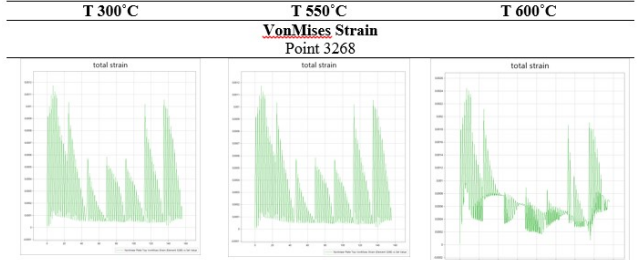

Fig. 3.3.4.d. VonM Strain in point 3268

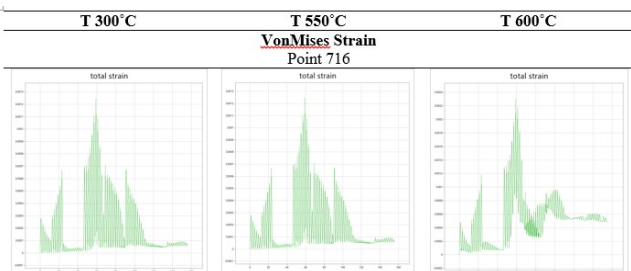

Fig. 3.3.4.e. VonM Strain in point 716

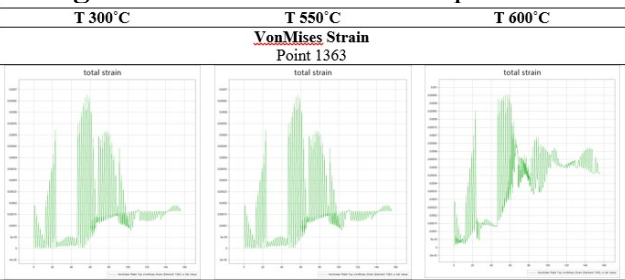

Fig. 3.3.4.f. VonM Strain in point 1363

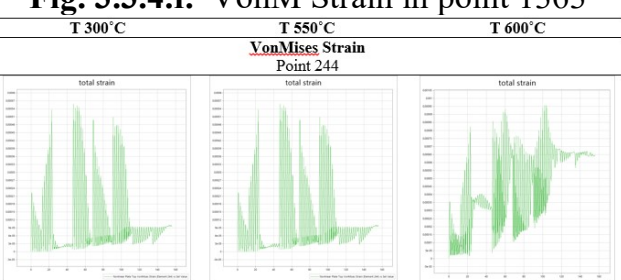

Fig. 3.3.4.g. VonM Strain in point 244

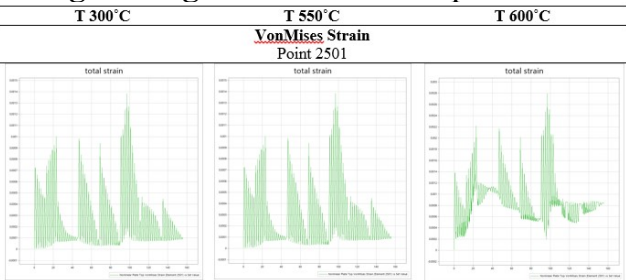

Fig. 3.3.4.h VonM Strain in point 2501

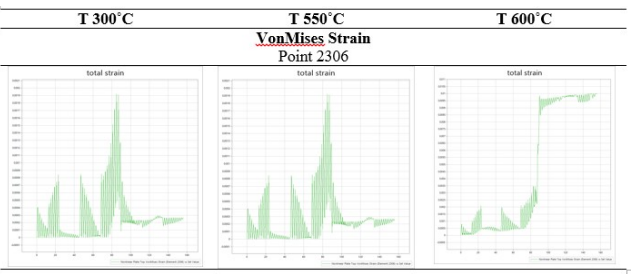

Fig. 3.3.4.i. VonM Strain in point 2306

\section{CONCLUDING REMARKS}

Considering the obtained results, further conclusions are formulated [2]:

1. From the point of view of plastic strain and total strain, it can be noticed that the two cases of $300^{\circ} \mathrm{C}$ and $550^{\circ} \mathrm{C}$ are leading 
to similar behaviour. For the thermal case of $600^{\circ} \mathrm{C}$, the plastic strain has been obtained in all the reference points, increasing significantly the total strain [2].

2. The case of $600^{\circ} \mathrm{C}$ leads to major residual changes of the structure of the panel. For practical purpose, a combination of the three thermal values can be used, in order to lead to a process after heating the structure, capable to eliminate the initial deformation that might occur usually during the welding process [2].

3. According the deformation results, by comparing the three thermal analyses, it can be noticed again that the case with $600^{\circ} \mathrm{C}$, is undoubtedly different to the first two, having maximal deformations around $25 \mathrm{~mm}$ for $600^{\circ} \mathrm{C}$, compared to around $3 \mathrm{~mm}$ for the other two cases [2].

4. Heat straightening is a complex procedure with implications in the material properties and in the total cost of the ship building process. It is of great interest to continuously study the process and to find the optimal parameters and patterns to counteract the negative effect of the welding process distortion [2].

\section{Acknowledgements}

The authors wish to express their thanks to VARD Shipyard Braila, who granted the experimental panel and technical data. The research was supported by the Research Centre of the Naval Architecture Faculty at "Dunarea de Jos" University of Galati.

\section{REFERENCES}

[1]. Saeed S., Eslam R., Mehdi I. "Effect of sequence and stiffener shape on welding distortion of stiffened panel", Journal of Constructional Steel Research 149, 2018, p. 4152.

[2]. Iatan C. "Non-linear finite element analysis of ship panels under thermal loads from technological process. Evaluation of the residual plastic strains and deformations", Master Thesis, Faculty of Naval Architecture, Galati 2020.

[3]. Structural Damage Control, Inc. "Heatstraightening repairs of damaged steel bridges, Federal Highway administration"

[4]. FNN 2020 Femap/NX Nastran user's guide, Simens PLM Software Inc.

Paper received on October $31^{\text {st }}, 2020$ 